\title{
Jóvenes y representaciones sociales sobre la foto de perfil en Facebook
}

Adolescents and social representations about the profile picture on Facebook

\author{
Adriana Rubiano Rubiano \\ Licenciada en Humanidades y Lengua Castellana \\ Mágister en Investigación Social Interdisciplinaria, Universidad Distrital \\ Candidata a magíster en Comunicación, Desarrollo y Cambio Social, \\ Universidad Santo Tomás (Colombia) \\ jazminrubiano@usantotomas.edu.com
}

Artículo de investigación

Fecha de recepción: Junio 13 de 2015 • Fecha de aprobación: Julio 2 de 2015

\section{RESUMEN}

Este artículo pretende recoger cómo se llevó a cabo una investigación cuyo eje central fue identificar cuáles son las representaciones que tienen los jóvenes de 14 a 17 años de un colegio en Bogotá (Colombia) de la localidad de Usme, sobre cómo son o qué quieren dar a entender los amigos de dichos jóvenes en Facebook a través de su foto de perfil. Se hace el recorrido desde los antecedentes, el marco teórico, el diseño metodológico que se usó, hasta llegar finalmente a una categorización que realizaron los sujetos de la investigación y que permite interpretar cuáles son las representaciones sociales que allí se encuentran inmersas. Por último, unas conclusiones que aparecen como producto de un ejercicio de investigación cualitativo, hermenéutico y participativo.

Palabras clave: representación, jóvenes, enunciación, imagen, fotografía, perfil. 


\begin{abstract}
This article seeks to provide data collected through a research, whose main focus is aimed at identifying the representations that young people aged 14 to 17 years old, have in a school located at Usme (south of Bogotá, Colombia). It presents perceptions about what they are, what they want to show through their Facebook profile picture. The article presents the background, the theoretical framework, the methodological design used, and finally, a categorization that was conducted by the research subjects which try to explain what social representations are immersed in. Finally, conclusions appear as a result of a qualitative, hermeneutical and participatory exercise research.
\end{abstract}

Keywords: representation, youth, enunciation, image, photo, profile. 


\section{INTRODUCCIÓN}

En los contextos actuales en donde la información está a la orden del día, especialmente en internet, han emergido otras formas de socialización diferentes a las tradicionales, en donde los encuentros entre personas ya no son como solían ser antes de la década del noventa, tan presenciales desde el punto de vista físico; más bien se ha optado por contactar y mantener interacción con los demás a través de plataformas virtuales que contienen en sí mismas elementos tan variados como: imágenes, fotografías, información personal; éstas incluso brindan la posibilidad de chatear, compartir datos, música, enlaces y otros elementos y herramientas que utiliza la web. Una de las redes virtuales que mayor acogida ha tenido a nivel mundial es la denominada Facebook, la cual surge en la Universidad de Harvard. Esta red fue creada por Mark Zuckerberg, quien la desarrolló en primera instancia para uso de los estudiantes de su universidad en el 2004. Rápidamente empezó a extenderse por muchas universidades prestigiosas de Estados Unidos de América.

En Facebook, las personas tienen la posibilidad de publicar fotos, las cuales pueden ser guardadas en álbumes cuya privacidad depende de las especificaciones que le brinde el propietario de cada cuenta, pero la foto de perfil o imagen que se coloque en este espacio, es accesible a cualquier persona dado que es pública. De ahí que el perfil en Facebook y las imágenes que allí se publican, sea un espacio virtual que puede generar un sinfín de representaciones en los usuarios que las observan, sobre quién es y cómo es la persona que la publicó. Lo problemático aparece cuando esas representaciones se alejan demasiado de la realidad de quien las publica, ocasionando en los sujetos una serie de construcciones de sentido erróneas o que se alejan mucho de la intención que tenía quien publicó determinada foto o imagen en su perfil; o por otro lado, pueden generar en los usuarios el caer en engańos o en ideas que, aunque falsas, pueden alterar o influenciar la imagen o perspectiva que se tenga sobre alguien, lo que puede ser aprovechado por quienes quieren, por ejemplo, aprovecharse de ciertas situaciones u obtener ventajas a través de su imagen.

En este trabajo se buscó rastrear cuáles son las principales representaciones de algunos jóvenes sobre el otro, específicamente desde la foto o imagen de perfil de quienes tengan agregados en calidad de "amigos" y con quienes no mantenían una relación 
muy cercana. Lo anterior, dado que se pudo identificar con los actores sociales en cuestión, que muchos de los "amigos" que tienen agregados, no necesariamente comparten una amistad o trato personal frecuente.

Por otro lado, cabe mencionar que este proceso investigativo es pertinente en nuestro actual contexto, en tanto las dinámicas sociales se conectan cada vez más con las interacciones y sentidos que circulan a través de la red, las cuales en muchas ocasiones se permean por las representaciones que tenemos sobre los demás. Así, la forma en que tratamos o pretendemos entender quién es el otro se ve cada vez más conectada por las imágenes que se vinculan a él. La pertinencia de esta investigación está dada también por el hecho de que si sabemos cuáles son las principales representaciones que se hacen los jóvenes sobre sus amigos en Facebook, se pueden crear algunos puntos de análisis que redunden en un proceso de reflexión sobre qué significa leer una imagen o foto de perfil, hasta qué punto ciertas imágenes se vinculan con quién y cómo es el otro, por ejemplo en la vida cotidiana.

Por último, esta investigación se justifica como investigación de la Maestría en Comunicación, Desarrollo y Cambio Social de la Universidad Santo Tomás (Colombia), en tanto permite analizar cómo a través de ciertos lenguajes de la imagen -específicamente la foto de perfil-, puestos a disposición a los usuarios a través de una red social como Facebook, se generan ciertos lenguajes que se materializan en representaciones que se conectan con los procesos de comunicación en que se ven inmersos los usuarios. Adicional a ello, esta investigación se ubica en un esfuerzo por interpretar desde qué lugares de significación y de enunciación se ubican los sujetos a la hora de interpretar una imagen de perfil y qué relación tiene esto con el tipo de representaciones que se generan desde allí.

\section{MARCO TEÓRICO}

Como punto de partida se rastreó la literatura que existe actualmente sobre jóvenes y nuevas formas de interacción social, especialmente través de redes sociales virtuales en internet, entre la cual se retoma el trabajo realizado por Rubio (2010), quien señala en su estudio cómo los jóvenes a través del uso que han venido dando a las 
nuevas tecnologías y, específicamente de las redes sociales, se han ido convirtiendo en gestores de una transformación no solamente sobre cómo se maneja actualmente el ocio, sino de qué manera se está dando hoy en día la interacción entre los miembros de la sociedad en su conjunto. Este es un punto de partida importante a la hora de realizar un análisis sobre representaciones conectadas con una red social como Facebook, en tanto nos muestra cómo es a partir de los jóvenes y de su manera de comprender y relacionarse con lo digital, como se están creando ciertas pautas de relación, agrupación y comportamiento social que van más allá de lo presencial, para ir navegando cada vez más en las redes de lo virtual.

Otro estudio sobre juventud que se retomó es el realizado por Regillo (2007), quien desarrolla cómo los jóvenes no deben ya seguir siendo identificados como aquellos seres carentes de una posición sobre todos los órdenes que le rodean; contrario a ello, defiende cómo estos se han venido apropiando de ciertas herramientas de comunicación que les permiten crear estrategias de protección ante un orden social que los excluye, las cuales estarían cargadas por un trasfondo de participación del sujeto joven en la construcción y trasformación del tejido social. Esta posición sobre el joven como un sujeto capaz de ser propositivo, que utiliza los instrumentos que tiene a la mano para presentar otras alternativas de comprender la realidad, es interesante y valioso para este trabajo en tanto se parte de que el joven, al ser capaz de identificar las representaciones de otros jóvenes con relación a una red social (Facebook), es capaz de generar un proceso crítico y analítico que le permita manejar cada vez más conscientemente un espacio virtual como éste, en pro de crear propuestas de interacción alternativas a las ya aceptadas como válidas.

Entre otras investigaciones sobre redes sociales y jóvenes que se revisaron se encuentra además el realizado por Mazón (2011), para quien en la virtualidad (como contexto de interacción que se da a través de la red) se aplicarían las mismas reglas del comportamiento que en el mundo real, lo cual significa que la virtualidad nos afecta debido a que los demás se percibirían como presencias reales. De ahí que el resultado positivo o negativo que tengamos producto de esos contactos sí puede intervenir en la forma como nos percibimos a nosotros mismos. Lo que interesa de esta postura para esta investigación es la idea de que, efectivamente, aquellos movimientos, interacciones y experiencias que se generan a partir de una red social 
virtual como Facebook, sí tienen la capacidad de afectar a las personas en ese mundo de afuera o presencial, especialmente en la imagen que se tiene sobre ellos mismos. En conexión con la relación entre la representación de sí mismo y la imagen que se proyecta en las redes sociales cabe mencionar el trabajo de Marwick (2005, citado por Almansa,Fonseca y Castillo, 2013) para quien los individuos son capaces de construir una imagen de sí ante los demás, la cual se manifestaría primordialmente en el tipo de imágenes que se publican, a partir de las que se buscaría ante todo la aceptación tanto real como virtual. De hecho, este autor aduce cómo a partir de las redes sociales, se realizan procesos de negociación de la propia identidad, en los cuales la imagen juega un papel preponderante.

Existen además trabajos sobre las redes sociales que se han centrado más en los procesos de privacidad y amistad. Así, por ejemplo, para Skog (2005) (citado por Almansa, Fonseca y Castillo, 2013), las interacciones que se dan desde la red no son pasivas; contrario a ello los usuarios participarían activamente en la evolución de la misma. Esto es interesante para la presente investigación, pues no se parte de que los usuarios simplemente observen una serie de imágenes de perfil, sin que exista un proceso en donde quien la observa participa a su vez en la configuración de la representación sobre el otro.

Por otro lado, el sustento teórico que alimentó esta investigación tuvo en cuenta algunas categorías, como la de representación, porque es el eje en cual se ubica el interés de la misma. Se retoma el concepto de Moscovici (1985) para quien las representaciones son, ante todo, el conjunto de conceptos opiniones, actitudes, valoraciones imágenes y explicaciones producto de la vida cotidiana y que se encuentran sustentadas por la comunicación.

Las representaciones sociales estarían, a su vez, relacionadas con la parte individual, desde lo cognitivo y lo social, como las creencias, las valoraciones, las emociones, junto con cualquier otra estructura, representación, proceso mental o memorístico que haya intervenido en el discurso y en la interacción. Claramente la perspectiva que nos proporciona Van Dijk (1984) es importante en para este estudio, en tanto el análisis que se haga acerca de cómo se generan las representaciones de los jóvenes sobre los otros desde la foto de perfil de sus amigos, se hará tanto desde un punto 
individual, del sujeto en sí, como desde los discursos sociales que están atravesando todo el tiempo esas representaciones.

Ahora, las representaciones que nos interesan en este trabajo son específicamente sobre imágenes, en tanto son fotos de perfil, un tipo de imagen muy característico de estos tiempos; de ahí que otra categoría central en este trabajo fue la de imagen, entendida esta como la réplica visual que simula la realidad, pero sin desconocer la influencia cultural desde donde se configuran representaciones. Esta categoría es trabajada además desde Debray (1992), para quien a través de la historia, la imagen ha pasado por diferentes estadios; el primero de ellos la logósfera, término que el autor enlaza directamente con lo sagrado, con ese estadio en el que el ser humano creía fervientemente que, a través de la imagen, era posible capturar la esencia de lo sagrado; estaba a su vez conectada con la muerte y con la posibilidad de traer a este mundo la presencia de un Dios o de un difunto, es decir la imagen tenía un halo sagrado y era ante todo un ser, una presencia y tenía un carácter de ídolo que se sitúa más en el campo de una existencia espiritual; en grafósfera la imagen se convierte en arte, en representación, es decir la imagen ya no es en sí misma un objeto de adoración porque se encarne de alguna manera en el objeto, sino que está en vez de otra cosa, pero remite a su original o a aquello que evoca. Tiene sentido en tanto lleva a la percepción a ciertos estados de contemplación que la elevan por encima de lo sensible; por último en la videósfera, la imagen ha perdido su capacidad para representar, se ha convertido más en un signo autoreferencial, es decir queda vaciada de un sentido que remita a otra cosa, su finalidad es más la de entretener y vender. Es decir, en este estadio la imagen no es ya concebida ni como un objeto sagrado que se convierte en el foco de adoración porque contenga en sí misma a la entidad, ni es la representación de otra cosa que está situada en el mundo bien de lo sensible o de lo concreto, sino que es un signo que lleva en sí mismo la opción de cambiar de sentido, de fluctuar en los océanos de la significación que son volátiles por naturaleza. La imagen se convierte en imagen de sí misma, en una especie de signo vacío de contenido que se llena de sentido en su fluctuación nunca inmóvil, y que negocia ese sentido con el usuario y con la red de significados que se tejen en los medios a través de la interacción con otros. 
Este último estadio de la mirada de la imagen se conecta con la investigación realizada en tanto sitúa lo visual y su sentido en la percepción y en el campo de la simulación, es decir de la creación de lo existente a través de la mirada, no solo propia sino en consonancia con las de otros.

Dicha mirada es efectuada por un sujeto, entendido como aquel que ha llegado a tener un grado importante de complejidad; es alguien que es capaz de tener un punto de vista sobre la realidad en la medida en que interactúa todo el tiempo con ella. Este es el sujeto que describe Cruz (1996), cuando afirma que es aquel capaz de generar una discrepancia entre él y la realidad de las cosas a partir de una actividad autónoma que le permite hacer elecciones y, por tanto, tomar una posición frente a la vida.

Cabe mencionar que el tipo de sujeto que interesa en esta investigación es el sujeto que además es joven, entendiéndolo no como aquel que no es adulto, sino como un agente de cambio que, a su vez, es un sujeto porque tiene consciencia de su ser en el mundo para sí mismo y para los otros (Muñoz, 2012). Dichos jóvenes son capaces de posicionarse en la realidad y transformarla, realizando un proceso de consciencia que los lleve a descubrir que la realidad y, en general, los ambientes en que se desenvuelven -bien sean virtuales o presenciales- también los configuran a ellos.

Ahora bien, la mirada o representación de los sujetos-jóvenes está mediada por una serie de discursos que incluyen la voz de otros y hacen parte de unos actos de enunciación que funcionan como acontecimientos discursivos, que crean versiones de lo percibido en el mundo, entendiendo los actos de enunciación como aquellos en donde tanto el sujeto que produce el enunciado, como aquel que lo lee, tiene unas intenciones, actitud y posición desde donde se habla (Ducrot, 1986), Dichos discursos están cargados de una serie de voces que pertenecen a otros, es decir son textos eminentemente polifónicos (Ducrot, 1986); en otras palabras, están cargados no solamente por la voz del enunciador, de sus intereses e intenciones, sino que en un texto es posible identificar múltiples voces que a veces no son tan explícitas, pero sí marcan una influencia en lo que se pretende decir. Para el caso de esta investigación, se retoma de la polifonía la relación que puede tener con la generación de ciertos tipos de representaciones sobre las fotos de perfil de los jóvenes sobre sus amigos en Facebook. Lo anterior se desarrolla un poco mejor en las conclusiones y en el 
análisis de las representaciones que aparecen más adelante, pero se adelanta que en las representaciones de los jóvenes, aparecen un marcado número de voces, perspectivas y lugares de la enunciación de diferentes actores sociales, instituciones, entre otras fuentes de producción discursiva que emergen en los contextos sociales en que se desenvuelven los sujetos-jóvenes.

\section{MetodoloGía}

Teniendo claridad sobre el entramado teórico que sustenta esta investigación, se pasa a describir cómo fue el diseño metodológico del mismo. En primer lugar se señala que se trabajó con una muestra de 30 jóvenes estudiantes de un colegio distrital de la localidad de Usme en Bogotá y que se encuentran realizando octavo grado.

Esta investigación es cualitativa y se ubica en el paradigma hermenéutico-interpretativo, desde el cual se analizaron las representaciones desde la experiencia registrada en este caso, desde un ámbito virtual como lo es la plataforma de Facebook. Interesó llegar a los significados a través de la interpretación juiciosa de las intencionalidades y capas ocultas de las construcciones simbólicas y representaciones de los estudiantes sobre los amigos que tienen en Facebook a partir de la imagen del perfil de algunos de ellos. Para hacerlo, se tuvo en cuenta que la conciencia humana es ante todo histórica y sociocultural, siendo su principal vehículo el lenguaje (Albert, 2007), por lo cual puede decirse que este trabajo se ubicaría en la tradición fenomenológicahermenéutica de enfoque interpretativo.

Ahora bien, los jóvenes con quienes se trabajó son estudiantes de grado décimo, entre los 14 y 17 años, pertenecientes al colegio distrital Fernando González Ochoa de la localidad de Usme en Bogotá, Colombia. Dicha institución se encuentra ubicada en la parte más central de la localidad (Virrey), lo cual beneficia a los habitantes del barrio, quienes tienen acceso a mejores infraestructuras, transporte, entre otros aspectos en comparación con quienes viven más en la periferia de la localidad. Dichos jóvenes se caracterizan por pertenecer a estratos socioeconómicos que oscilan entre el 1 y el 2. La mayoría de ellos viven en condiciones de pobreza, que aunque no es extrema, sí se manifiesta en la mayoría de las familias. Tal condición de pobreza no 
limita el acceso que los estudiantes tienen a la tecnología, específicamente a internet, dado que en su mayoría, los estudiantes poseen y llevan una actividad constante en algunas redes sociales tales como Facebook y Twitter, bien sea desde sus casas o en lugares comerciales que brindan este servicio.

\section{¿Cómo se recolectaron los datos?}

Para realizar el proceso de recolección de datos se diseñaron unas fases, las cuales permitirían al investigador ir recolectando la información de manera progresiva. En la primera parte se hizo una sensibilización con los estudiantes que participaron sobre cómo veían ellos la importancia de las fotos de perfil en Facebook en la actualidad. Luego, se pidió que llevaran una serie de fotos de perfil de personas que tuvieran agregadas a sus cuentas personales de Facebook, pero con quienes no tuvieran una relación muy cercana; es decir personas de quien no conocieran mucho en lo presencial. Se pide que realicen desde su punto de vista una categorización con respecto a cómo podrían clasificarse esas fotos de acuerdo a la intención y significado que se les puede dar. En una segunda fase se realizó con los estudiantes una colcha de retazos (Hernández, Fernández y Baptista, 2003), técnica propia de la investigación participativa para tratar de identificar tanto el tipo de representaciones que los estudiantes tenían sobre las fotos de perfil de sus amigos, como la forma en que esas imágenes se podrían conectar con lo que los sujetos de la investigación creían sobre las personas de las fotos. La colcha de retazos permitió identificar qué subpreguntas -en tanto la pregunta central sí fue proveída por la investigadora- encontraban los estudiantes con respecto a la relación entre la foto de perfil y la percepción de los jóvenes frente a quiénes son y cómo son sus amigos en Facebook. Cada participante respondía a las preguntas las cuales fueron socializadas y escogidas por el grupo, con las respuestas se armaba la colcha de retazos que luego fue socializada para encontrar entre todos una primera categorización sobre el tipo de representaciones que aparecen al interpretar la foto de perfil de un amigo en Facebook.

Por último, se realizaron unas entrevistas en profundidad (Albert, 2007) con 10 estudiantes que habían participado en los talleres anteriores, lo cual permitió complementar y profundizar más en la información que se estaba recolectando. Las preguntas tenían que ver con el tipo de clasificaciones que se hacen al comparar varias 
fotos de perfil (20), así como con la forma en que ellos tienen para leer ese tipo de fotos; de la misma forma se indagó si ellos encontraban o no relación con las fotos de perfil y el modo de ser en lo presencial de esas mismas personas.

Después de tener todos los datos, se procedió a la interpretación de los mismos, siguiendo el diseño metodológico que se describió anteriormente. Cabe destacar que en una de las fases de la interpretación, los mismos sujetos de la investigación en compañía del investigador, identificaron las principales categorías en que se podrían clasificar las fotos de perfil en Facebook, lo cual arrojó, grosso modo, los siguientes resultados:

Tabla 1. Categorías de fotos de perfil en Facebook.

\begin{tabular}{|c|c|}
\hline Tipos de fotos de perfil & Análisis del investigador con los sujetos de la investigación \\
\hline Los mostrones & $\begin{array}{l}\text { Las personas que suben este tipo de fotos quieren aparentar muchas } \\
\text { veces lo que no son o parecer más atractivos frente a los demás. }\end{array}$ \\
\hline Los ficticios o creídos & $\begin{array}{l}\text { Utilizan muchos objetos, en especial prendas de vestir y accesorios } \\
\text { que les permitan bien demostrar, bien aparentar que se tienen los } \\
\text { medios económicos para vivir holgadamente y menospreciar así a } \\
\text { los demás. }\end{array}$ \\
\hline Las sociales & $\begin{array}{l}\text { Serían personas que no soportan la soledad y que les gusta que los } \\
\text { demás los sigan, les gusta ser reconocidos porque son aceptados por } \\
\text { otros. }\end{array}$ \\
\hline $\begin{array}{l}\text { Las que muestran } \\
\text { filiaciones o preferencias } \\
\text { (deportiva, pertenecer a } \\
\text { algún grupo) }\end{array}$ & $\begin{array}{l}\text { Las personas que ponen este tipo de fotos quieren ganar adeptos } \\
\text { para sus causas, les gusta que los demás sepan de su devoción o } \\
\text { gusto por un equipo, por una causa. Esto lo hacen porque quieren } \\
\text { definir ante los demás cómo son. }\end{array}$ \\
\hline Las familiares & $\begin{array}{l}\text { Estas fotos demostrarían que se tiene una familia sólida, que no se } \\
\text { tienen problemas al interior de la misma, aunque muchas veces en } \\
\text { verdad eso no sea cierto. }\end{array}$ \\
\hline Las sensuales & $\begin{array}{l}\text { Quienes publican estas fotos buscan que los demás sepan y los } \\
\text { reconozcan como personas atractivas. En muchas ocasiones se } \\
\text { quiere generar atracción en el sexo de su predilección, ganar likes, } \\
\text { sentirse poderosos a través de ciertos atributos sexuales. }\end{array}$ \\
\hline
\end{tabular}


Campos en Ciencias Sociales

\begin{tabular}{|c|c|}
\hline Tipos de fotos de perfil & Análisis del investigador con los sujetos de la investigación \\
\hline $\begin{array}{l}\text { Las caras (serias, graciosas, } \\
\text { picos) }\end{array}$ & $\begin{array}{l}\text { Los estados de ánimo se reflejarían en esas caras, si se está triste o } \\
\text { feliz, se manifestaría en los gestos que se publican. Aunque varios } \\
\text { sujetos de la investigación señalaban que, en muchas ocasiones, esas } \\
\text { caras son solo apariencias de lo que se quiere mostrar a los demás, } \\
\text { sin que esto sea necesariamente cierto. }\end{array}$ \\
\hline Cuerpo entero & $\begin{array}{l}\text { Se quiere mostrar que se es muy atractivo y ganar adeptos, o que } \\
\text { no se tiene ningún complejo con relación al propio cuerpo. Serían } \\
\text { personas que se aceptan mucho como son, aunque también se } \\
\text { seńala que muchos aparentarían lo que quieren ser, mas no lo que } \\
\text { son. }\end{array}$ \\
\hline Religiosas & $\begin{array}{l}\text { Se quiere demostrar que se es fervoroso en el amor hacia Dios. } \\
\text { Se buscarían adeptos, pero a veces solo se aparenta una devoción } \\
\text { religiosa, sin que necesariamente se sienta o se practique en } \\
\text { realidad. }\end{array}$ \\
\hline $\begin{array}{l}\text { Imágenes (ánime, animales, } \\
\text { etc.), no fotos personales }\end{array}$ & $\begin{array}{l}\text { Se tiene alguna inseguridad con relación a mostrar el cuerpo o } \\
\text { el rostro. El no mostrar es una evidencia de que se tiene una } \\
\text { carencia de algún tipo, especialmente desde lo físico. Para ellos } \\
\text { quienes se niegan a mostrar su cara o cuerpo, serían personas que } \\
\text { probablemente no se sienten cómodas o felices con ellas mismas. } \\
\text { Aunque también se señalaba que esas imágenes podían representar } \\
\text { sus gustos y preferencias y cómo sus amigos en Facebook querían } \\
\text { que los demás los reconocieran. }\end{array}$ \\
\hline Graciosas & $\begin{array}{l}\text { Se quiere alegrar a los demás o demostrar que se tiene un buen } \\
\text { sentido del humor y la necesidad de compartirlo con otros. }\end{array}$ \\
\hline Los enamorados & $\begin{array}{l}\text { Quieren que los demás sepan que están enamorados y son } \\
\text { felices. Quieren que los envidien por su dicha o alejar a posibles } \\
\text { competidores. }\end{array}$ \\
\hline Los viajeros & $\begin{array}{l}\text { Quieren mostrar a los demás que se tiene el poder adquisitivo para } \\
\text { salir y conocer diferentes lugares. Quieren verse felices y prósperos } \\
\text { frente a los otros. }\end{array}$ \\
\hline
\end{tabular}

Fuente: elaboración propia. 


\section{¿Cómo se podrían analizar estas representaciones?}

Las representaciones antes mencionadas, podrían categorizarse a su vez en algunos tipos, de acuerdo a su naturaleza, intencionalidades, sentidos evidentes y ocultos, de la siguiente manera:

\section{Representaciones que demarcan apariencias: ser o parecer}

En este tipo de representación los jóvenes son reiterativos en afirmar que muchas de las fotos de perfil que ellos observan, no demarcan necesariamente cómo son sus amigos en Facebook en la vida fuera de la red virtual, existe una fuerte sospecha sobre el falseamiento de la información, donde hay un fingimiento que se centra en la imagen que se quiere mostrar frente a los demás. De hecho, la palabra apariencia que utilizan muchos de los sujetos de la investigación, se conecta para ellos con lo que no es verdad, como el mecanismo para engañar a otros para ganar algún beneficio, el cual es por lo general el de ser reconocidos, diferenciados y valorados positivamente por los demás.

En este tipo de representaciones cobra una gran importancia llamar la atención de otros, aunque para hacerlo, se valgan de objetos, posturas corporales, gestos que no necesariamente tienen correspondencia con el tipo de dinámicas que se ven en lo cotidiano.

Aparte de lo anterior, las representaciones de este tipo le apuntan a que los jóvenes en muchas ocasiones muestran a través de sus fotos de perfil lo que quisieran ser, no lo que que son realmente. Es decir, proyectarían en ellas el deseo de cómo quieren ser vistos por los demás, antes que necesariamente cómo son y eso lo perciben los jóvenes sujetos de esta investigación, diciéndolo de hecho en repetidas ocasiones en las entrevistas y clasificaciones que ellos mismos realizaron.

\section{Representaciones de felicidad o bienestar}

Para la mayoría de los jóvenes que participaron en la investigación era bastante evidente que sus amigos en Facebook difícilmente publicarían fotos en donde 
aparecieran momentos, rostros o gestos que llevaran a pensar que se era infeliz o que se estaba atravesando por un mal momento. Lo anterior porque según lo analizado en las entrevistas y en las respuestas que se obtuvieron de forma participativa, el parecer de una persona que tiene bienestar o es feliz, atrae más la atención y los likes de los amigos en Facebook. Aparecer como una persona feliz podría producir más popularidad que dar la impresión de ser una persona que sufre. Lo anterior podría analizarse desde el tipo de relatos que se ha vendido desde la modernidad cuando, de alguna manera, se predetermina de antemano y desde muchos discursos más bien económicos, cómo es el estilo de vida que puede definir o no qué se entiende por prosperidad y, por supuesto, por felicidad. Lo anterior atraviesa incluso los discursos sobre cómo debe verse físicamente una persona cuando es feliz, en compañía de quienes, con qué tipo de objetos e incluso en qué momento de la vida podría ser deseable obtenerlos.

Los jóvenes señalaban incluso que para poder aparentar esa prosperidad, muchos de sus amigos en Facebook se valían de algunos objetos que en sociedad se consideraban exclusivos o costosos, lo cual generaba que en varias fotos sus amigos aparecieran con elementos que demarcan cierta distinción social, todo bajo la intención de demostrar cómo sus vidas se ajustan a ciertos estándares que se han ido normalizando como los deseables o adecuados en la vida actual.

Desde la sociología, Lipovetsky (1990) señala que el sistema económico vigente genera en los individuos un proceso que denomina personalización, en donde se va incorporando a través de los medios un deseo por adquirir más y más artículos de consumo, generando la ilusión de que es el individuo desde su poder volitivo quien decide qué consumir; sin embargo, señala el autor, lo que ocurre es que se generan una serie de discursos que llevan a los individuos a creer que se están eligiendo objetos, servicios y opciones de vida desde un proceso personal, cuando en realidad lo que ocurre es que se escoge desde lo que puede adquirir o se muestra como deseable en el mercado. Lo anterior nos sirve en tanto aquellos objetos que se consideran exclusivos y que demarcan cierta distinción social, están conectados con las dinámicas que genera el mercado y que se normalizan a través de estrategias varias, entre ellas las provistas por los discursos publicitarios. 


\section{Representaciones sobre el reconocimiento}

Varias de las categorías sobre las fotos de perfil apuntan a representaciones sobre lo importante que es ser reconocido positivamente al interior de la red social, para lo cual la foto de perfil juega un papel preponderante. La representación del reconocimiento se alimenta por ciertos indicios que hacen parte de la lógica y estructura propia de la plataforma, por ejemplo la opción de dar likes, que en muchas ocasiones genera la representación en los jóvenes de ser o no reconocidos o visibilizados por los otros, lo cual redundaría muy posiblemente en ser aceptados o no, no solo en el contexto virtual, sino incluso en el presencial.

El reconocimiento en Facebook, específicamente el que se da por la popularidad que demuestran ciertas fotos de perfil a través de los likes y comentarios, llevaría a que aquello que los demás digan sobre la persona sea más positivo, lo cual afectaría positiva o negativamente su popularidad. Lo anterior dado que será muy importante "encajar", siendo una forma de hacerlo el parecer diferente, aunque se haga prácticamente lo mismo. Se trata de ser aceptados, por lo cual los comentarios de los demás serán puntos clave a la hora de relacionarse con los otros.

Cabe anotar que pese a que esta representación sobre la importancia de ser reconocido por otros es muy fuerte, la mayoría de los jóvenes de la investigación acepta que muchas de las fotos que publican sus amigos denotan esa ansia de ser reconocidos, en ocasiones aparentando situaciones, emociones y una abundancia económica que muchas veces no se ajusta con la realidad.

\section{Representaciones sobre las fotos narcisistas}

En la mayoría de las categorías mencionadas anteriormente, los jóvenes señalaban cómo sus amigos en Facebook asumían en muchas de sus fotos de perfil unas posturas corporales, entre las que se incluían algunas de carácter sensual que obedecían a la necesidad de aparentar o mostrar unos atributos, pero por lo general exagerando el atractivo que se quiere proyectar para atraer al sexo de su preferencia. Lo anterior, afirmaban los jóvenes, lleva a las personas a obsesionarse con su propia imagen, de la misma forma en que lo hacía Narciso, llevando a que el ritual de la selfie se 
convierta en una parte fundamental de la lógica que se maneja en Facebook. Si a esto le agregamos que los narcisistas siempre competirán con otros por verse diferentes, actualizados, existirá una lucha contra el tiempo por verse cada vez de forma nueva, pues el tiempo es líquido y efímero y lo viejo va cediendo en cuestión de pocas horas el lugar a una imagen cada vez más nueva y también autorreferencial, vacía de un sentido que escapa hacia lo fluctuante (Debray, 1992).

\section{Representaciones sobre la emocionalidad}

Un elemento interesante de análisis sobre el tema de la emocionalidad y las fotos de perfil consiste en que la mayoría de los jóvenes de la investigación consideran que a partir de los gestos, de las posturas del cuerpo o de si se pone o no una foto de perfil o en vez de ello se utiliza una imagen religiosa o de alguna preferencia, etc., se estarían reflejando ciertos estados emocionales e incluso psicológicos de la persona. Así, por ejemplo, cuando una persona aparece con un gesto de tristeza o su imagen de perfil se ve sombría, podría significar que en su vida podrían estar ocurriendo sucesos difíciles; por el contrario, si la persona se muestra feliz, en compañía de otros y en una actitud de bienestar, esto reflejaría un buen estado de ánimo y la capacidad para socializar mejor; así mismo, si alguien se niega a poner una foto de sí mismo, esto puede entenderse como que se trata de una persona que tiene complejos o inseguridades. Lo anterior nos llevaría a pensar que, a pesar de que en lo referente al físico y económico los sujetos jóvenes sospechan de la veracidad de esas imágenes, cuando se trata de la parte emocional, los jóvenes tienden mucho a asociar que aquello que se proyecta en este nivel, corresponde la mayor parte de las veces con el momento anímico por el que pasan sus amigos en Facebook. Lo anterior puede tener implicaciones interesantes porque nos permite pensar que, por ejemplo, cuando se trata de engańar a un joven a través de una foto de perfil en Facebook, este sería blanco más fácil desde lo que se proyecta en lo emocional que desde lo puramente concreto o material, bien sea desde el cuerpo como desde los objetos.

\section{Representaciones que reflejan ansia de poder}

Por último, el tipo de fotos de perfil que identificaron los jóvenes denota que entre más se muestre que se cambia rápidamente el escenario o el tipo de objetos con 
los que se aparece, se posee una posibilidad de viajar, de tener ropa a la moda, el celular, el reloj más costoso posible, que se sale con más personas o que se es más atractivo denotando un ansia de poder de quienes publican ciertas fotos de perfil; no obstante, la representación más clara frente a esta ansia de poder, es que se aparenta en la mayoría de los casos sobre lo que no se tiene, para mantener una imagen que le brinde a quien la publica un estatus en todos los campos, sin que por ello se escape de la sospecha del lector de la imagen, quien vería con desconfianza aquello que el otro por lo general quiere aparentar.

\section{CONCLUSIONES}

- Las representaciones que hacen los estudiantes de la muestra sobre sus amigos en Facebook, a partir de sus fotos de perfil, dicen en primera medida, cómo interpreta el mundo quien ve la fotografía, cuáles son sus prejuicios, temores e ideas.

- Las representaciones de los jóvenes son ante todo sociales y polifónicas, es decir se van conformando no solo a partir de la información que se puede inferir de las fotos, sino que están cargadas con otras voces, prejuicios, ideas e imaginarios que se encuentran en el entorno social y cultural de los sujetos. De ahí que las representaciones resultantes sobre quiénes son y cómo son sus amigos en Facebook, no solo contiene la voz y la posición de quien lee la foto, sino la de una cantidad enorme de actores sociales y sus actos de enunciación, los cuales están cargados de intencionalidades y lugares diversos de enunciación.

- Los factores que influyen en la construcción de la representación que se hace un sujeto sobre sus amigos en Facebook a partir de su foto de perfil son ante todo simbólicos, es decir, la foto se lee no solamente como un todo, sino que se desglosa en los microcomponentes semióticos, como por ejemplo gestos, objetos, posturas del cuerpo que la conforman, existiendo después un todo significativo, que es el que luego conforma una representación más global.

- Los sujetos de la investigación no creen ciegamente en que a partir de una foto de perfil se pueda llegar a conocer realmente cómo es una persona desde lo 
presencial; es más, en muchas oportunidades se señalaba cómo las fotos que se publicaban de perfil simulan una realidad que en muchas ocasiones, dista de conectarse con la forma en que los individuos se relacionan y se muestran en otros contextos sociales.

Lo anterior nos lleva a pensar en que el sujeto que se expone a una serie de signos autorreferentes (Debray, 1992) de la videósfera, no necesariamente cree ingenuamente aquello que la imagen parece sugerirle. Es decir, los sujetos están en la capacidad de sospechar que aquel contenido de los signos-fotos de perfil que aparecen en forma de imágenes quieren expresar ideas, estados, emociones y situaciones que podrían ser falsos. Lo anterior abre la discusión sobre el carácter activo de los lectores de fotos de perfil y, en general consumidores de signos, dado que el sujeto se reafirma como tal en la medida en que tiene la capacidad de dudar, de discutir, de sospechar. Es decir, los sujetos, pese a la exposición que tienen a un sinfín de signos que cada vez están más vacíos de contenido y que parecen querer llevarlos a ciertos estereotipos diversos, están en la capacidad de encontrar los intersticios, lo baches, las mentiras que aparecen en la imagen y formar así representaciones que ponen en duda aquello que tiene apariencia de verdad. 


\section{REFERENCIAS}

Almansa, A., Fonseca, O., y Castillo, A. (2013). Redes sociales y jóvenes. Uso de Facebook en la juventud colombiana y española. Revista Comunicar, 20, (pp. 127-135).

Albert, M. (2007). La investigación educativa. Madrid: McGraw-Hill.

Centro Internacional de Investigación para el Desarrollo. (2004). El sistema de análisis social. Recuperado de https:/www.upeace /pdf/ALL\%20SAS\%20SPANISH.pdf

Cruz, M. (1996). Tiempo de subjetividad. En Cruz, M. (Ed.). Barcelona: Ediciones Paidós.

Debray, R. (1992). Vida y muerte de la imagen. Barcelona: Paidós.

Ducrot, O. (1986). El decir y lo dicho: polifonía de la enunciación. Barcelona: Paidós.

Hernández, R., Fernández, C., y Baptista, P. (2003). Metodología de la Investigación. 3.a ed. México: McGraw-Hill.

Lipovetsky, G. (1990). La era del vacio: ensayos sobre el individualismo. Barcelona: Anagrama Editorial.

Marwick, A. (2005). I'm a lot more interesting than a friendster profile: identity presentation, authenticity, and power in social networking services. En Almansa, A., Fonseca, O., y Castillo, A. (Comp.). Redes sociales y jóvenes. Uso de Facebook en la juventud colombiana y española. Revista Comunicar, 20, (pp. 127-135).

Mazón, R. (2011). Estoy en Facebook, luego existo. La identidad y las redes sociales. Revista de Filosofia, 131, (pp. 243-268). 
Moscovici, S. (1985). La era de las multitudes: un tratado de la psicología de las masas. México: Fondo de cultura económica.

Muñoz, G. (2012). Jóvenes, culturas y poderes. Revista Latinoamericana de Ciencias sociales, niñez y juventud, 10(1), 712-714.

Regillo, R. (2007). Emergencia de culturas juveniles: estrategias del desencanto. Colombia: Grupo editorial Norma.

Rubio, G. (2010). Generación digital: patrones de consumo de internet, cultura juvenil y cambio social. Revista de Estudios de Juventud, 88, (pp. 201-221).

Skog, A. (2005). Social interaction in virtual communities: The significance of technology. En Almansa, A., Fonseca, O., y Castillo, A. (Comp.). Redes sociales y jóvenes. Uso de Facebook en la juventud colombiana y española. Revista Comunicar, 20, (pp. 127-135).

Van Dijk, T. (1984). Texto y contexto. Madrid: Cátedra ediciones. 